\title{
Pain Among an Inpatient Complex Chronic Care Population of Residents with and without Missing Limbs
}

\author{
Meaghan Ferguson' \\ Anton Svendrovski (D) ${ }^{2}$ \\ Joel Katz $\mathbb{D}^{\prime}$ \\ 'Faculty of Health, Department of \\ Psychology, York University, Toronto, \\ Ontario, Canada; ${ }^{2}$ UZIK Consulting Inc., \\ Toronto, Ontario, Canada
}

Purpose: Limb loss occurs for various reasons (trauma, infection, vascular diseases, tumors, congenital absence). Limb loss is known to result in several types of pain. Little is known about pain in residents with missing limbs admitted to complex chronic care (CCC) facilities. This study examined the presence of pain and its intensity in $\mathrm{CCC}$ residents with and without missing limbs.

Methods: The Continuing Care Reporting System was accessed for data from residents admitted to Ontario com $\backslash$ plex chronic care facilities assessed with the Resident Assessment Instrument Minimum Data Set, V2.0. Propensity score matching (1:1 ratio) was used to identify a control resident without missing limbs for each case. McNemar's test was used for dichotomous pain $(\mathrm{Y} / \mathrm{N})$ and Wilcoxon Signed Ranks test for ordinal pain (4-level and 7-level pain variables). Binary and multinomial logistic regression were used to quantify the relationship between missing limbs and reports of pain.

Results: Missing limbs were reported by 2961 residents $(2.1 \%$, original $n=139,920)$ resulting in 2212 propensity matched pairs. A significantly higher proportion of missing limb cases had pain $(80 \%)$ versus controls $(70 \%), \chi^{2}=64.43, p<0.001$. Significantly higher pain levels were found in cases versus controls $(z=8.47, p<0.001$ for 4-level pain; $z=8.57, p<0.001$ for 7-level pain). Residents with missing limbs were 1.46 (95\% CI: 1.26-1.70) times more likely to report pain than controls, $p<0.001$.

Conclusion: The results point to the need to better manage pain in CCC residents with missing limbs.

Keywords: complex, disease, chronic, amputation, health

\section{Introduction}

Limb amputation can occur for various reasons including trauma, infection, vascular diseases, and tumors. Following limb amputation, it is alarmingly common for patients to continue to experience painful sensations referred to the phantom limb. Phantom limb sensations (PLS) are often present following amputation and described as if the limb was still present. ${ }^{1}$ These sensations can manifest as itching, tingling, and feelings of warmth or coldness. ${ }^{2,3}$ Others report the phantom limb sensations to be same as those experienced before the amputation. ${ }^{4}$ Many patients, unfortunately, report these experiences to be extremely painful. Post-amputation pain is commonly separated into two categories: residual limb pain (RLP), formally known as "stump pain" and defined as pain that originates from the actual site of the amputation; and, phantom limb pain (PLP), clinically defined as pain that is experienced as arising from the missing 
limb. ${ }^{1,5-8}$ PLP is characterized by intense episodes of pain, described by patients as throbbing, "electric shock", cramped, and stabbing sensations, and can be a debilitating condition that can significantly reduce mobility, quality of life, and psychological wellbeing. ${ }^{9}$ Epidemiological studies indicate that up to $95 \%$ of patients report post-amputation pain $^{10}$ and $85 \%$ reported significant pain even decades after amputation. $^{8}$

Although PLP and RLP are most commonly reported in the literature, with noted incidence rates of $50 \%$ $80 \%,{ }^{11-14}$ there is ample evidence that pain in other body sites also is a prominent problem for amputees. Mazzone et $\mathrm{al}^{12}$ recently found that $49 \%$ of amputees experience recurrent back pain, while Esfandiari et al reported a staggering $69 \%$ of patients reported chronic back pain. In addition to back pain, ${ }^{13-17}$ other prevalent pain locations include the neck and shoulder, ${ }^{5,18-21}$ contra-lateral and ipsilateral knee, and ipsilateral hip. ${ }^{13,14}$

Similar to many other clinical conditions, the presence of PLP, RLP and general pain among amputees can be exacerbated by the presence of additional disease morbidity, and subsequently increase the demand for medications and treatments, and contribute to poorer prognoses. ${ }^{7,22}$ The complex chronic disease (CCD) population may be especially vulnerable. ${ }^{23} \mathrm{~A} C \mathrm{CD}$ is a condition involving multiple morbidities (MM) and a combination of functional, ${ }^{24,25}$ social, $^{26}$ vocational $^{27}$ and/or mental health challenges. ${ }^{28}$

Despite the complexities associated with pain among amputees, as well as the challenges of MM among a CCD population, very little is known about the comorbidity and interaction of these clinical presentations, particularly as they relate to pain. In light of this lack of understanding of amputee-related pain and disease complexity within an elderly, CCD population, the objective of this study is to investigate pain and related variables in a large sample of inpatient CCD residents with limb amputations.

\section{Methods}

\section{Data Source}

This study used data from the Canadian Institute for Health Information (CIHI) Facility-Based Continuing Care Reporting System (CCRS), which captures information on individuals admitted to publicly-funded hospital facilities for complex chronic care in Canada (Continuing Care Reporting System, 2013-2014) between the years 2006-2016. Upon entry to a complex chronic care (CCC) facility, residents are administered a standardized assessment protocol, the
Resident Assessment Instrument - Minimum Data Set/Full Assessment (RAI-MDS/FA 2.0 Canadian Version), within 14 days of admission. If the resident remains in the facility for longer than 92 days, quarterly assessments are conducted. These assessments are typically completed by the treating nurse or physician and include resident self-reports and information from medical files.

The RAI-MDS/FA 2.0 is an internationally validated clinical assessment instrument. ${ }^{29-34}$ This standard tool collects a wide array of information, including basic demographic characteristics, diagnostic profiles, medication usage and treatment participation, and outcomes, as well as categorizes diseases.

The study was reviewed and approved by the York University research ethics board (Human Participants Research Committee) prior to receiving the data from the Canadian Institutes of Health Information.

\section{Missing Limb Diagnosis and Propensity Score Matching (PSM)}

The original full CCRS dataset consisted of 139,920 residents, of whom 2961 were documented to have a "missing limb". The classification of missing limb was taken directly from the CCRS RAI-MDS/FA 2.0. Propensity score matching was used to create two groups of residents: cases (with missing limb) and controls (no missing limb), using a 1:1 ratio ensuring the case and control residents had the exact same value for age, gender, marital status, assessment year and total disease count. Propensity score matching is a procedure that matches case records with a similar control record, within the single dataset. The procedure initially runs a logistic regression with the case and control group variables as the dependent variable. Following this, it selects a match for each case from the control group based on the propensity score obtained in the logistic regression. This score is an estimate of the probability of membership in the case group. Ultimately, a second dataset is created that includes cases and matched controls.

\section{Pain Measures}

The CCRS RAI-MDS/FA 2.0 measures pain using two descriptive scales:

1. Frequency: No pain (0), pain less than daily (1), pain daily (2); and,

2. Intensity: Mild pain (1), moderate pain (2), times when pain is horrible or excruciating (3). 
For the present study, we created three measures of pain by combining various items from the above two existing CCRS RAI/MDS/FA 2.0 scales:

1)Pain-Yes/No (P-Y/N): Pain prevalence dichotomous measure: no pain (0); pain (1) (mild, moderate, severe);

2)4-point pain intensity scale (PI-4): No pain (0), mild pain (1), moderate pain (2), severe pain (3).

\section{Research Objective and Data Analysis}

The primary research objective was to examine the difference in pain between residents with and without missing limbs. All data used in this study is derived from the initial assessment of all residents, aged 18-101 years, from Ontario's CCC facilities between the years 2006-2016, reported in the CIHI CCRS dataset. For non-parametric data, we used Mann-Whitney test, McNemar test for dichotomous pain and Wilcoxon Signed Ranks test for ordinal pain (PI-4).

Multinomial binary logistic regression analysis was conducted to evaluate the secondary research objective of exploring the relationship between missing limb, sex and the missing limb by sex interaction and pain (Pain-Y/N, PI-4). All regression models were conducted controlling for the following potential confounders: Activities of Daily Living (ADL) scores, Depression Rating Scale (DRS) scores, Index of Social Engagement (ISE) Scores, number of medications taken, and days taking analgesics. All descriptive and inferential statistical analyses were performed using SPSS (version 27), $p<0.05$ was considered statistically significant.

\section{Results}

The original dataset contained 139,920 resident records of whom 2961 were coded as missing limb. The propensity score matching algorithm found exact matches for 2212 cases. Each of the 2212 missing limb cases was matched with a similar resident in the control subgroup without a missing limb, this representing a final dataset of 2212 paired samples for analysis. Table 1 provides a description of the matched cases and controls.

The comparison of pain between residents with and without missing limb was conducted using McNemar test and Wilcoxon Signed Ranks tests (Table 2). We observed a significantly higher proportion of missing limb cases with pain (80\%) compared to controls $(70 \%)$, McNemar test $\chi^{2}=64.43, p<0.001$. Wilcoxon Signed Ranks tests also showed significantly higher pain levels among cases compared to controls $(z=8.47, p<0.001$ for 4-level pain).
We observed a higher proportion of cases reporting moderate pain $(48 \%)$ and severe pain (11\%) compared to controls (39\% and $9 \%$, respectively).

Among residents with missing limb, females reported significantly higher pain compared to males, $p=0.013$ dichotomous pain, $p=0.004$ 4-point pain scale, and $83 \%$ of females and $78 \%$ of males reported pain (based on dichotomous measure) (Table 3). Among control residents (without missing limb), females reported significantly higher pain than males, $p<0.001$ dichotomous pain, $p<$ 0.0014 -point pain scale (Table 4).

Binary logistic regression was used to further quantify the relationship between residents with missing limbs and pain reports, with the dependent variable being dichotomous pain. Results are presented in Table 5. We observed that residents with missing limbs were 1.37 (95\% CI 1.161.61) times more likely to report pain compared to controls, $p<0.001$, when controlling for relevant covariates. Tables 6 and 7 examine the interaction of the covariates.

Multinomial logistic regression model was used to further quantify the relationship between missing limb status and ordinal level of pain (PI-4). The dependent variable for this model was 4-level pain. The independent variable was missing limb (no missing limbs was the reference category). Results are presented in Table 8 . We observed that residents with missing limbs were 1.47 (95\% CI 1.23-1.75) times more likely to report moderate pain ( $p$ $<0.001)$ and $1.57(1.22-2.03)$ times more likely to report severe pain $(\mathrm{p}<0.001)$.

Multinomial logistic regression models were used to test the relationship between pain (dichotomous, 4-level) and missing limb, sex and their interaction term. The dependent variable for this model was pain. Independent variables were missing limb, sex, and the missing limb by sex interaction. Results are presented in Table 9.

\section{Discussion}

The results of the present large-scale study indicate that the presence and severity of pain was significantly higher in CCC residents with a missing limb, compared to a propensity matched cohort not missing a limb, even after adjusting for potential confounding variables which may influence pain risks. In fact, residents with missing limbs were 1.50 (95\% CI 1.23-1.83) times more likely to report mild, moderate and severe pain compared to controls, $p<0.001$ (Table 9). Additional analysis showed that residents with a missing limb were more likely to report moderate pain (48\%) and severe pain (11\%), compared to 
Table I Descriptive Characteristics of Matched Samples

\begin{tabular}{|c|c|c|c|}
\hline \multirow[t]{2}{*}{ Characteristics } & Cases $(n=2212)$ & Controls $(n=2212)$ & \multirow{2}{*}{$\begin{array}{l}\text { Comparison Between Two } \\
\text { Groups }\end{array}$} \\
\hline & $\begin{array}{l}\text { N (\%) or Mean } \pm \text { SD Median } \\
\text { (IQR) }\end{array}$ & $\begin{array}{l}\text { N (\%) or Mean } \pm \text { SD Median } \\
\text { (IQR) }\end{array}$ & \\
\hline $\begin{array}{l}\text { Gender } \\
\text { Females } \\
\text { Males }\end{array}$ & $\begin{array}{l}826(37 \%) \\
1386(63 \%)\end{array}$ & $\begin{array}{l}826(37 \%) \\
1386(63 \%)\end{array}$ & $\chi^{2}(I)=0.00, p=1.00$ \\
\hline Age & $73.58 \pm 11.11$ & $73.58 \pm 11.11$ & $\mathrm{t}(4422)=0.00, p=1.00$ \\
\hline $\begin{array}{l}\text { Year of assessment } \\
2006 \\
2007 \\
2008 \\
2009 \\
2010 \\
2011 \\
2012 \\
2013 \\
2014 \\
2015 \\
2016\end{array}$ & $\begin{array}{l}202(9 \%) \\
194(9 \%) \\
186(8 \%) \\
221(10 \%) \\
211(10 \%) \\
226(10 \%) \\
228(10 \%) \\
242(11 \%) \\
232(11 \%) \\
227(10 \%) \\
43(2 \%)\end{array}$ & $\begin{array}{l}202(9 \%) \\
194(9 \%) \\
186(8 \%) \\
221(10 \%) \\
211(10 \%) \\
226(10 \%) \\
228(10 \%) \\
242(11 \%) \\
232(11 \%) \\
227(10 \%) \\
43(2 \%)\end{array}$ & $\chi^{2}(10)=0.00, p=1.00$ \\
\hline $\begin{array}{l}\text { Number of comorbidities (excluding missing } \\
\text { limb) } \\
0-1 \\
2 \\
3 \\
4 \\
5 \\
6 \\
7 \\
8 \\
9 \\
10+\end{array}$ & $\begin{array}{l}5.89 \pm 2.52 \\
47(2 \%) \\
119(6 \%) \\
228(10 \%) \\
304(14 \%) \\
336(15 \%) \\
347(16 \%) \\
267(12 \%) \\
215(10 \%) \\
163(7 \%) \\
186(8 \%)\end{array}$ & $\begin{array}{l}5.89 \pm 2.52 \\
47(2 \%) \\
119(6 \%) \\
228(10 \%) \\
304(14 \%) \\
336(15 \%) \\
347(16 \%) \\
267(12 \%) \\
215(10 \%) \\
163(7 \%) \\
186(8 \%)\end{array}$ & $\chi^{2}(9)=0.00, p=1.00$ \\
\hline $\begin{array}{l}\text { Marital status } \\
\text { Never married } \\
\text { Married } \\
\text { Widowed } \\
\text { Separated } \\
\text { Divorced } \\
\text { Unknown }\end{array}$ & $\begin{array}{l}266(12 \%) \\
1135(5 \mid \%) \\
560(25 \%) \\
26(1 \%) \\
123(6 \%) \\
102(5 \%)\end{array}$ & $\begin{array}{l}266(12 \%) \\
1135(51 \%) \\
560(25 \%) \\
26(1 \%) \\
123(6 \%) \\
102(5 \%)\end{array}$ & $\chi^{2}(5)=0.00, p=1.00$ \\
\hline $\begin{array}{l}\text { Activities of Daily Living (ADL) score [long } \\
\text { form] }\end{array}$ & $15.20 \pm 7.75$ & $16.46 \pm 8.07$ & $\mathrm{t}(4422)=5.30, p<0.001$ \\
\hline Depression Rating Scale (DRS) score & $1.31 \pm 2.02$ & $1.57 \pm 2.27$ & $\mathrm{t}(4407)=3.94, p<0.001$ \\
\hline Index of Social Engagement (ISE) & $3.40 \pm 1.99$ & $2.92 \pm 2.03$ & $\mathrm{t}(4422)=8.04, p<0.001$ \\
\hline Number of medications taken & $14.20 \pm 5.73$ Median (IQR): I4 (6) & $12.43 \pm 5.16$ Median (IQR): $12(6)$ & $\begin{array}{l}\mathrm{t}(4422)=10.82, p<0.001 \mathrm{M}-\mathrm{W} \\
p<0.001\end{array}$ \\
\hline Days taking analgesics & $5.17 \pm 2.8 \mathrm{I}$ Median (IQR): 7 (4) & $4.42 \pm 3.12$ Median (IQR): 7 (7) & $\begin{array}{l}t(4422)=8.44, p<0.001 M-W \\
p<0.001\end{array}$ \\
\hline
\end{tabular}

(Continued) 
Table I (Continued).

\begin{tabular}{|c|c|c|c|}
\hline \multirow[t]{2}{*}{ Characteristics } & Cases $(n=2212)$ & Controls $(n=2212)$ & \multirow{2}{*}{$\begin{array}{l}\text { Comparison Between Two } \\
\text { Groups }\end{array}$} \\
\hline & $\begin{array}{l}\text { N (\%) or Mean } \pm \text { SD Median } \\
\text { (IQR) }\end{array}$ & $\begin{array}{l}\text { N (\%) or Mean } \pm \text { SD Median } \\
\text { (IQR) }\end{array}$ & \\
\hline Number of emergency room visits & $0.57 \pm 1.22$ Median (IQR): 0 (I) & $0.57 \pm 0.89$ Median (IQR): 0 (I) & $\mathrm{t}(4422)=0.11, p=0.91 \mathrm{M}-\mathrm{W}$ \\
\hline 0 & $1353(61 \%)$ & $1218(55 \%)$ & $p=0.001$ \\
\hline 1 & $660(30 \%)$ & $825(37 \%)$ & \\
\hline 2 & $123(5 \%)$ & III (5\%) & \\
\hline 3 & $32(2 \%)$ & $28(1 \%)$ & \\
\hline 4 & $17(1 \%)$ & $14(1 \%)$ & \\
\hline 5 or more & $22(1 \%)$ & II (I\%) & \\
\hline Number of physician visits & $4.78 \pm 3.13$ Median (IQR): 4 (4) & $4.98 \pm 3.29$ Median (IQR): $4(5)$ & $\begin{array}{l}t(4422)=2.11, p=0.035 M-W \\
p=0.13\end{array}$ \\
\hline Hospital stays & I.I7 \pm 1.04 Median (IQR): I (I) & $1.08 \pm 1.29$ Median (IQR): I (0) & $\mathrm{t}(44 \mid 2)=2.44, p=0.015 \mathrm{M}-\mathrm{W}$ \\
\hline 0 & $510(23 \%)$ & $543(25 \%)$ & $p<0.001$ \\
\hline 1 & $1108(50 \%)$ & $1204(55 \%)$ & \\
\hline 2 & 401 (18\%) & $336(15 \%)$ & \\
\hline 3 & $126(6 \%)$ & $86(4 \%)$ & \\
\hline 4 or more & $62(3 \%)$ & $38(1 \%)$ & \\
\hline
\end{tabular}

Note: $M-W$ is Mann-Whitney non-parametric test.

Table 2 Comparison of Dichotomous Pain (P-Y/N) and 4-Point Pain Scale (PI-4) Between Cases (Missing Limb) and Controls (No Missing Limb), $n=2212$ in Each Group

\begin{tabular}{|c|c|c|c|}
\hline Pain Variable & $\begin{array}{l}\text { Cases (Missing Limb) } \\
\text { N (\%) }\end{array}$ & $\begin{array}{l}\text { Controls (No Missing Limb) } \\
\text { N (\%) }\end{array}$ & Statistical Comparison Test \\
\hline $\begin{array}{l}\text { P-Y/N } \\
\text { No pain } \\
\text { Pain (mild, moderate or } \\
\text { severe) }\end{array}$ & $\begin{array}{l}44 \mid(20 \%) \\
|77|(80 \%)\end{array}$ & $\begin{array}{l}672(30 \%) \\
1540(70 \%)\end{array}$ & McNemar test $\chi^{2}=64.43, p<0.001$ \\
\hline $\begin{array}{l}\text { PI-4 } \\
\text { Mean } \pm \text { SD* } \\
\text { No pain (0) } \\
\text { Mild pain (I) } \\
\text { Moderate pain (2) } \\
\text { Severe pain (3) }\end{array}$ & $\begin{array}{l}1.50 \pm 0.94 \\
441(20 \%) \\
463(21 \%) \\
1059(48 \%) \\
249(11 \%)\end{array}$ & $\begin{array}{l}1.26 \pm 0.99 \\
672(30 \%) \\
484(22 \%) \\
863(39 \%) \\
193(9 \%)\end{array}$ & $\begin{array}{l}\text { Wilcoxon Signed Ranks test } z=8.47 \text {, } \\
p<0.001\end{array}$ \\
\hline
\end{tabular}

Note: *Mean and SD represent the mean and standard deviation of the rank ordered pain scores.

controls (39\% and 9\%, respectively) (Table 2). Females had statistically significantly higher odds of reporting pain than males. The sex by missing limb interaction term was not significant for any of the three pain variables.

Despite the significant health care concerns and pain problems among this population, the CCD population with missing limbs has remained unexplored in relation to pain. Among a population of CCD residents, the current study used a case-control design using propensity matching, which allowed for the comparison of two demographically similar groups of residents with and without missing limbs. Groups were matched with a 1:1 ratio on important demographic variables, including sex, age, marital status, assessment date and comorbid disease count. The present results provide evidence of a relationship between pain and CCD residents with missing limbs. However, it is important to note that the CCRS coding system used to denote whether or not a resident received a code of "missing limb" is crude and the database does not contain important information typically provided in studies of people who have undergone amputation (eg, time since amputation; reason for amputation; limb, level, and side of 
Table 3 Comparison of Dichotomous Pain (P-Y/N) and 4-Point Pain Scale (PI-4) Between Males and Females with Missing Limb (Cases, $\mathrm{n}=2212$ )

\begin{tabular}{|l|l|l|l|}
\hline Pain Variable & Females n = 826 (37\%) & Males $\mathbf{n}=1386(\mathbf{6 3} \%)$ & Statistical Comparison Test \\
\hline P-Y/N & & & Chi-square test $\chi^{2}=6.23, p=0.013$ \\
No & $142(17 \%)$ & $299(22 \%)$ & \\
Yes & $684(83 \%)$ & $1087(78 \%)$ & Mann-Whitney U-test $z=2.90, p=0.004$ \\
\hline PI-4 & & $1.46 \pm 0.94$ & \\
Mean \pm SD* & $1.58 \pm 0.92$ & $299(22 \%)$ & \\
No pain (0) & $142(17 \%)$ & $297(21 \%)$ & \\
Mild pain (I) & $166(20 \%)$ & $644(47 \%)$ & \\
Moderate pain (2) & $415(50 \%)$ & $146(10 \%)$ & \\
Severe pain (3) & $103(13 \%)$ & $014 \%$ & \\
\hline
\end{tabular}

Note: *Mean and SD represent the mean and standard deviation of the rank ordered pain scores.

Table 4 Comparison of Dichotomous Pain (P-Y/N) and 4-Point Pain Scale (PI-4) Between Males and Females Without Missing Limb (Controls, $n=2212$ )

\begin{tabular}{|c|c|c|c|}
\hline Pain Variable & Females $n=826(37 \%)$ & Males $n=1386(63 \%)$ & Statistical Comparison Test \\
\hline \multicolumn{4}{|l|}{$\mathrm{P}-\mathrm{Y} / \mathrm{N}$} \\
\hline No & 197 (24\%) & 475 (34\%) & Chi-square test $\chi^{2}(I)=26.58, p<0.001$ \\
\hline Yes & $629(76 \%)$ & $911(66 \%)$ & \\
\hline \multicolumn{4}{|l|}{ PI-4 } \\
\hline Mean \pm SD* & $1.39 \pm 0.95$ & $1.18 \pm 1.00$ & Mann-Whitney U-test $z=4.90, p<0.001$ \\
\hline No pain $(0)$ & 197 (24\%) & 475 (34\%) & \\
\hline Mild pain (I) & $186(22 \%)$ & $298(22 \%)$ & \\
\hline Moderate pain (2) & $364(44 \%)$ & $499(36 \%)$ & \\
\hline Severe pain (3) & 79 (10\%) & $114(8 \%)$ & \\
\hline
\end{tabular}

Note: *Mean and SD represent the mean and standard deviation of the rank ordered pain scores.

Table 5 Binary Logistic Regression Models Dichotomous Pain (P-Y/N)

\begin{tabular}{|l|l|c|c|c|}
\hline Independent Variable & Dependent Variable & B (SE) & p-value & OR (95\% CI) \\
\hline Missing limb & P-Y/N & & & \\
& No & $-0.315(0.083)$ & $<0.001$ & $0.73(0.62-0.86)$ \\
& Yes & $0.315(0.083)$ & $<0.001$ & $1.37(1.16-1.61)$ \\
\hline
\end{tabular}

Note: All analyses (reported odds ratios) are controlled for ADL, number of medications taken, DRS, ISE, days taking analgesics, number of emergency room visits and days of physician visits.

Abbreviation: OR, odds ratio.

amputation; number of limbs amputated; whether the pain recorded was residual limb pain, phantom limb pain or pain unrelated to amputation). It is recommended that future versions of the RAI/MDS FA include more detailed information on amputation location and cause. Nevertheless, the results clearly show that CCC residents who received a code of "missing limb" reported greater pain severity and were significantly more likely to report moderate and severe pain than the matched sample not coded as "missing limb" even after controlling for important confounders including psychosocial factors and medication use.

There is a large literature examining the phenomena of post-amputation phantom limb pain and residual limb pain; unfortunately, the CCD population has been overlooked in this area, despite the high prevalence of individuals with amputated limbs among these patients. Given the noted prevalence of pain in the phantom limb/stump pain research, reported chronic pain among CCD population, and the large number of residents qualified as having 
Table 6 Binary Logistic Regression Models Dichotomous Pain (P-Y/N)

\begin{tabular}{|c|c|c|c|}
\hline Independent Variables & B (SE) & p-value & OR (95\% Cl) \\
\hline Missing limb & $0.315(0.083)$ & $<0.001$ & $1.37(1.16-1.61)$ \\
\hline$A D L$ & $0.013(0.006)$ & 0.023 & $1.01(1.00-1.02)$ \\
\hline Number of medications taken & $0.022(0.008)$ & 0.009 & $1.02(1.01-1.04)$ \\
\hline DRS & $0.039(0.021)$ & 0.060 & $1.04(1.00-1.08)$ \\
\hline ISE & $0.052(0.023)$ & 0.021 & $1.05(1.01-1.10)$ \\
\hline Days taking analgesics & $0.373(0.013)$ & $<0.001$ & $1.45(1.41-1.49)$ \\
\hline Number of emergency room visits & $0.050(0.047)$ & 0.286 & $1.05(0.96-1.15)$ \\
\hline Days of physician visits & $0.030(0.013)$ & 0.018 & $1.03(1.01-1.06)$ \\
\hline Intercept & $-1.422(0.180)$ & $<0.001$ & \\
\hline
\end{tabular}

Note: Dependent variable $=$ Pain (Yes).

Abbreviation: OR, odds ratio.

Table 7 Binary Logistic Regression Models Dichotomous Pain (P-Y/N)

\begin{tabular}{|c|c|c|c|}
\hline Independent Variables & B (SE) & p-value & OR (95\% Cl) \\
\hline Missing limb & $-0.315(0.083)$ & $<0.001$ & $0.73(0.62-0.86)$ \\
\hline ADL & $-0.013(0.006)$ & 0.023 & $0.99(0.98-1.00)$ \\
\hline Number of medications taken & $-0.022(0.008)$ & 0.009 & $0.98(0.96-0.99)$ \\
\hline DRS & $-0.039(0.021)$ & 0.060 & $0.96(0.92-1.00)$ \\
\hline ISE & $-0.052(0.023)$ & 0.021 & $0.95(0.91-0.99)$ \\
\hline Days taking analgesics & $-0.373(0.013)$ & $<0.001$ & $0.69(0.67-0.7 \mathrm{I})$ \\
\hline Number of emergency room visits & $-0.050(0.047)$ & 0.286 & $0.95(0.87-1.04)$ \\
\hline Days of physician visits & $-0.030(0.013)$ & 0.018 & $0.97(0.95-0.99)$ \\
\hline Intercept & $\mathrm{I} .422(0.180)$ & $<0.001$ & \\
\hline
\end{tabular}

Note: Dependent variable $=$ Pain $($ No) .

Abbreviation: OR, odds ratio.

Table 8 Multinomial Logistic Regression Models for 4-Point Pain Scale (PI-4)

\begin{tabular}{|l|l|c|c|c|}
\hline Independent Variable & Dependent Variable & B (SE) & P-value & OR (95\% CI) \\
\hline Missing limb & Pl-4 & & & \\
& No pain & $-0.315(0.083)$ & $<0.001$ & $0.73(0.62-0.86)$ \\
& Mild pain & $0.196(0.097)$ & 0.043 & $1.22(1.01-1.47)$ \\
& Moderate pain & $0.382(0.091)$ & $<0.001$ & $1.47(1.23-1.75)$ \\
& Severe pain & $0.452(0.130)$ & $<0.001$ & $1.57(1.22-2.03)$ \\
\hline
\end{tabular}

Notes: No missing limb (control) is the reference category All analyses (reported odds ratios) are controlled for ADL, number of medications taken, DRS, ISE, days taking analgesics, number of emergency room visits and days of physician visits.

Abbreviation: OR, odds ratio.

a missing limb within the CCD data, the results of this research study highlight the prevalence of pain among a population of CCD patients identified has having "missing limbs", while taking into consideration the multiple morbidities of these residents.

Although PLP and RLP are the most commonly reported types of pain among amputees, there is evidence to suggest that pain, not directly related to the surgical amputation, but possibly associated with the limb loss due to biomechanical sequelae, is also problematic among amputees. Musculoskeletal pain, ${ }^{35,36}$ particularly upper and lower back pain, ${ }^{5,11,14,15,37-42}$ neck and shoulder pain, ${ }^{5,18-21}$ contra-lateral knee pain, ${ }^{13,21}$ ipsilateral hip pain, ${ }^{5,13}$ as well as other regional sites including knees, ${ }^{21}$ leg and foot, buttocks and hips, arms and hands, abdomen, and head, ${ }^{5}$ are also commonly reported, even on nonamputated sides..$^{21}$ Pain associated with a missing limb is also attributed with physical and psychosocial difficulties that can greatly interfere with an individual's quality of life. $^{43}$ 
Table 9 Binary and Multinomial Logistic Regression Models for Dichotomous Pain (P-Y/N), 4-Point Pain Scale (PI-4)

\begin{tabular}{|c|c|c|c|c|}
\hline Independent Variable & Dependent Variable & B (SE) & $p$-value & Odds Ratio ( $95 \% \mathrm{Cl}$ ) \\
\hline \multicolumn{5}{|l|}{ Model I: P-Y/N } \\
\hline \multirow[t]{2}{*}{ Missing limb } & No pain & $-0.404(0.102)$ & $<0.001$ & $0.67(0.55-0.82)$ \\
\hline & Pain & $0.404(0.102)$ & $<0.001$ & $1.50(1.23-1.83)$ \\
\hline \multirow[t]{2}{*}{ Female } & No pain & $-0.373(0.117)$ & 0.001 & $0.69(0.55-0.87)$ \\
\hline & Pain & $0.373(0.117)$ & 0.001 & $1.45(1.15-1.82)$ \\
\hline \multirow[t]{2}{*}{ Missing limb $\times$ Female } & No pain & $0.258(0.174)$ & 0.137 & $1.29(0.92-1.82)$ \\
\hline & Pain & $-0.258(0.174)$ & 0.137 & $0.77(0.55-1.09)$ \\
\hline \multicolumn{5}{|l|}{ Model 2: PI-4 } \\
\hline \multirow[t]{4}{*}{ Missing limb } & No pain & $-0.404(0.102)$ & $<0.001$ & $0.67(0.55-0.82)$ \\
\hline & Mild pain (I) & $0.284(0.119)$ & 0.017 & $1.33(1.05-1.68)$ \\
\hline & Moderate pain (2) & $0.481(0.112)$ & $<0.001$ & $1.62(1.30-2.01)$ \\
\hline & Severe pain (3) & $0.489(0.164)$ & 0.003 & $1.63(1.18-2.25)$ \\
\hline \multirow[t]{4}{*}{ Female } & No pain & $-0.373(0.117)$ & 0.001 & $0.69(0.55-0.87)$ \\
\hline & Mild pain (I) & $0.313(0.135)$ & 0.020 & $1.37(1.05-1.78)$ \\
\hline & Moderate pain (2) & $0.419(0.128)$ & 0.001 & $1.52(1.18-1.95)$ \\
\hline & Severe pain (3) & $0.340(0.189)$ & 0.072 & $1.40(0.97-2.04)$ \\
\hline \multirow[t]{4}{*}{ Missing limb $\times$ Female } & No pain & $0.258(0.174)$ & 0.137 & $1.29(0.92-1.82)$ \\
\hline & Mild pain (I) & $-0.26 \mathrm{I}(0.20 \mathrm{I})$ & 0.194 & $0.77(0.52-1.14)$ \\
\hline & Moderate pain (2) & $-0.278(0.187)$ & 0.138 & $0.76(0.52-1.09)$ \\
\hline & Severe pain (3) & $-0.131(0.263)$ & 0.620 & $0.88(0.52-1.47)$ \\
\hline
\end{tabular}

Note: All analyses (reported odds ratios) are controlled for ADL, number of medications taken, DRS, ISE, days taking analgesics, number of emergency room visits and days of physician visits.

Consistent with the general pain literature, ${ }^{44-48}$ we found that female residents had statistically significantly higher odds of reporting pain than males. However, within the phantom limb pain research, there is no clear difference in the incidence of pain between sexes. ${ }^{49}$ In line with these previous findings, the sex by missing limb interaction term was not significant for any of the three pain variables (Table 9), indicating pain that females and males with missing limbs did not differ from their counterparts without a missing limb. Overall, the results from this study point to the need to better manage pain in CCC residents with missing limbs.

\section{Conclusion}

To our knowledge, this is the first study to explore the relationship between individuals with a missing limb and reports of pain among a large population of CCD residents. The results of this study further emphasize that individuals with missing limbs report more pain prevalence than those without a missing limb. The results are consistent with previous research that supports the phenomenon associated with amputations/missing limbs and pain. Future research that includes further resident information about pain location, type, amputation causation, and follow-up assessments would be beneficial to this area of literature. Furthermore, future research studies should ideally incorporate validated, comprehensive pain measurement scales. Given the complexity of the CCD population, information that may better inform the understanding of pain and multimorbid diseases, and the subsequent treatment care of this specific population is invaluable in an aging society.

\section{Disclosure}

Dr. Joel Katz is supported by a Canadian Institutes of Health Research Canada Research Chair in Health Psychology at York University. The authors report no other conflicts of interest in this work.

\section{References}

1. Lundeberg T, Bondesson L, Lundströom V. Relief of primary dysmenorrhea by transcutaneous electrical nerve stimulation. Acta Obstet Gynecol Scand. 1985;64(6):491-497. doi:10.3109/ 00016348509156727

2. Flor H. Phantom-limb pain: characteristics, causes, and treatment. Lancet Neurol. 2002;1(3):182-189. doi:10.1016/S1474-4422(02) 00074-1 
3. Kooijman CM, Dijkstra PU, Geertzen JHB, et al. Phantom pain and phantom sensations in upper limb amputees: an epidemiological study. Pain. 2000;87(1):33-41. doi:10.1016/S0304-3959(00)00264-5

4. Katz J, Melzack R. Pain 'memories' in phantom limbs: review and clinical observations. Pain. 1990;43(3):319-336. doi:10.1016/03043959(90)90029-D

5. Ehde DM, Czerniecki JM, Smith DG, et al. Chronic phantom sensations, phantom pain, residual limb pain, and other regional pain after lower limb amputation. Arch Phys Med Rehabil. 2000;81 (8):1039-1044. doi:10.1053/apmr.2000.7583

6. Le Feuvre P, Aldington D. Know pain know gain: proposing a treatment approach for phantom limb pain. BMJ Mil Health. 2014;160(1):16-21.

7. Sherman RA, Sherman CJ, Bruno GM. Psychological factors influencing chronic phantom limb pain: an analysis of the literature. Pain 1987;28(3):285-295. doi:10.1016/0304-3959(87)90064-9

8. Sherman RA, Katz J, Marbach JJ, Heermann-Do K. Locations, characteristics and descriptions. In: Sherman RA, ed. Phantom pain. New York: Plenum Press; 1997:1-31.

9. Rothgangel A, Braun S, Smeets R, et al. Feasibility of a traditional and teletreatment approach to mirror therapy in patients with phantom limb pain: a process evaluation performed alongside a randomized controlled trial. Clin Rehabil. 2019;33 (10):1649-1660. doi:10.1177/0269215519846539

10. Hanyu-Deutmeyer AA, Cascella M, Varacallo M. Phantom Limb Pain. StatPearls; 2020.

11. Robbins CB, Vreeman DJ, Sothmann MS, et al. A review of the long-term health outcomes associated with war-related amputation. Mil Med. 2009;174(6):588-592. doi:10.7205/ MILMED-D-00-0608

12. Mazzone B, Farrokhi Shawn PT, Hendershot Brad, McCabe Cameron T, Watrous JR. Prevalence of Low Back Pain and Relationship to Mental Health Symptoms and Quality of Life After a Deploymentrelated Lower Limb Amputation. SPINE. 2020;45 (19):1368-1375. doi:10.1097/BRS.0000000000003525

13. Ebrahimzadeh $\mathrm{MH}$, Hariri S. Long-term outcomes of unilateral transtibial amputations. Mil Med. 2009;174(6):593-597. doi:10.7205/ MILMED-D-02-8907

14. Caddick N, Cullen H, Clarke A, et al. Ageing, limb-loss and military veterans: a systematic review of the literature. Ageing Soc. 2019;39 (8):1582-1610. doi:10.1017/S0144686X18000119

15. Ebrahimzadeh MH, Kachooei AR, Soroush MR, et al. Long-term clinical outcomes of war-related hip disarticulation and transpelvic amputation. JBJS. 2013;95(16):e114. doi:10.2106/JBJS.L.01160

16. Hoaglund FT, Jergesen HE, Wilson L, Lamoreux LW, Roberts R. Evaluation of problems and needs of veteran lower-limb amputees in the San Francisco Bay Area during the period 1977-1980. J Rehabil Res Dev. 1983;20(1):57-71.

17. Taghipour H, Moharamzad Y, Mafi AR, et al. Quality of life among veterans with war-related unilateral lower extremity amputation: a long-term survey in a prosthesis center in Iran. J Orthop Trauma. 2009;23(7):525-530. doi:10.1097/BOT.0b013e3181a10241

18. Davidson J. A comparison of upper limb amputees and patients with upper limb injuries using the Disability of the Arm, Shoulder and Hand (DASH). Disabil Rehabil. 2004;26(14-15):917-923. doi:10.1080/09638280410001708940

19. Durance JP, O'Shea BJ. Upper limb amputees: a clinic profile Int Disabil Stud. 1988;10(2):68-72. doi:10.3109/09638288809164107

20. Jones LE, Davidson JH. The long-term outcome of upper limb amputees treated at a rehabilitation centre in Sydney, Australia. Disabil Rehabil. 1995;17(8):437-442. doi:10.3109/096382895 09166658

21. Morgan SJ, Friedly JL, Amtmann D, et al. Cross-sectional assessment of factors related to pain intensity and pain interference in lower limb prosthesis users. Arch Phys Med Rehabil. 2017;98(1):105-113. doi:10.1016/j.apmr.2016.09.118
22. Weeks SR, Anderson-Barnes VC, Tsao JW. Phantom limb pain: theories and therapies. Neurologist. 2010;16(5):277-286. doi:10.1097/NRL.0b013e3181edf128

23. Lee R, Wong TY, Sabanayagam C. Epidemiology of diabetic retinopathy, diabetic macular edema and related vision loss. Eye Vision. 2015;2(1):1-25. doi:10.1186/s40662-015-0026-2

24. Rijiken M, Van Kerkhof M, Dekker J, Schellevis FG. Comorbidity of chronic disease: effects of disease pairs on physical and mental functioning. Qual Life Res. 2005;14:45-55.

25. Bayliss EA, Bayliss MS, Ware JE, et al. Predicting declines in physical function in persons with multiple chronic medical conditions: what we can learn from the medical problem list. Health Qual Life Outcomes. 2004;2(1):47. doi:10.1186/1477-7525-2-47

26. Noël PH, Chris Frueh B, Larme AC, et al. Collaborative care needs and preferences of primary care patients with multimorbidity. Health Expect. 2005;8(1):54-63. doi:10.1111/j.1369-7625.2004.00312.x

27. Kuluski K, Bensimon CM, Alvaro C, et al. Life interrupted: the impact of complex chronic disease from the perspective of hospitalized patients. Illn Crises Loss. 2014;22(2):127-144. doi:10.2190/IL.22.2.d

28. Fortin M, Bravo G, Hudon C, Lapointe L, Dubois MF, Almirall J. Psychological distress and multimorbidity in primary care. Ann Fam Med. 2006;4(5):417-422. doi:10.1370/afm.528

29. Fries BE, Simon SE, Morris JN, et al. Pain in US nursing homes: validating a pain scale for the minimum data set. Gerontologist. 2001;41(2):173-179. doi:10.1093/geront/41.2.173

30. Hartmaier SL, Sloane PD, Guess HA, et al. Validation of the minimum data set cognitive performance scale: agreement with the mini-mental state examination. J Gerontol a Biol Sci Med Sci. 1995;50A(2):M128-M133. doi:10.1093/gerona/50A.2.M128

31. Hawes C, Morris JN, Phillips CD, et al. Reliability estimates for the minimum data set for nursing home resident assessment and care screening (MDS). Gerontologist. 1995;35(2):172-178. doi:10.1093/geront/ 35.2.172

32. Mor V, Branco K, Fleishman J, et al. The structure of social engagement among nursing home residents. J Gerontol B Psychol Sci Soc Sci. 1995;50B(1):P1-P8. doi:10.1093/geronb/50B.1.P1

33. Snowden M, McCormick W, Russo J, et al. Validity and responsiveness of the minimum data set. $J$ Am Geriatr Soc. 1999;47 (8):1000-1004. doi:10.1111/j.1532-5415.1999.tb01297.x

34. Lawton MP, Casten R, Parmelee PA, et al. Psychometric characteristics of the minimum data set II: validity. J Am Geriatr Soc. 1998;46 (6):736-744. doi:10.1111/j.1532-5415.1998.tb03809.x

35. Østlie K, Lesjø IM, Franklin RJ, Garfelt B, Skjeldal OH, Magnus P. Prosthesis rejection in acquired major upper-limb amputees: a population-based survey. Disabil Rehabil Assist Technol. 2012;7 (4):294-303.

36. Postema SG, Bongers RM, Brouwers MA, et al. Musculoskeletal complaints in transverse upper limb reduction deficiency and amputation in the Netherlands: prevalence, predictors, and effect on health. Arch Phys Med Rehabil. 2016;97(7):1137-1145. doi:10.1016/j.apmr.2016.01.031

37. Ephraim PL, Wegener ST, MacKenzie EJ, et al. Phantom pain, residual limb pain, and back pain in amputees: results of a national survey. Arch Phys Med Rehabil. 2005;86(10):1910-1919. doi:10.1016/j.apmr.2005.03.031

38. Kulkarni J, Gaine WJ, Buckley JG, et al. Chronic low back pain in traumatic lower limb amputees. Clin Rehabil. 2005;19(1):81-86. doi:10.1191/0269215505cr819oa

39. Morgenroth DC, Orendurff MS, Shakir A, et al. The relationship between lumbar spine kinematics during gait and low-back pain in transfemoral amputees. Am J Phys Med Rehabil. 2010;89 (8):635-643. doi:10.1097/PHM.0b013e3181e71d90

40. Hammarlund CS, Carlström M, Melchior R, et al. Prevalence of back pain, its effect on functional ability and health-related quality of life in lower limb amputees secondary to trauma or tumour: a comparison across three levels of amputation. Prosthet Orthot Int. 2011;35 (1):97-105. doi:10.1177/0309364610389357 
41. Esfandiari E, Sanjari MA, Jamshidi AA, et al. Knee osteoarthritis at the early stage: the four-week effect of lateral wedge insole on pain and risk of falls. Med J Islam Repub Iran. 2018;32(1):17. doi:10.14196/mjiri.32.17

42. Mazzone CM, Liang-Guallpa J, Li C, et al. High-fat food biases hypothalamic and mesolimbic expression of consummatory drives. Nat Neurosci. 2020;23(10):1253-1266. doi:10.1038/s41593-020-0684-9

43. Chamlian TR, Bonilha MM, Macêdo MC, Rezende F, Leal CA. Prevalência De Dor Fantasma Em Amputados Do Lar Escola São Francisco. Acta fisiátrica; 2012.

44. Fillingim RB. Individual differences in pain: understanding the mosaic that makes pain personal. Pain. 2017;158(Suppl 1):S11. doi:10.1097/j.pain.0000000000000775

45. Kleiman V, Clarke H, Katz J. Sensitivity to pain traumatization: a higher-order factor underlying pain-related anxiety, pain catastrophizing and anxiety sensitivity among patients scheduled for major surgery. Pain Res Manag. 2011;16(3):169-177. doi:10.1155/2011/ 932590
46. Rogers AH, Gallagher MW, Garey L, et al. Pain anxiety symptoms scale-20: an empirical evaluation of measurement invariance across race/ethnicity, sex, and pain. Psychol Assess. 2020;32(9):818. doi: $10.1037 /$ pas 0000884

47. Sorge RE, Totsch SK. Sex differences in pain. J Neurosci Res. 2017;95(6):1271-1281. doi:10.1002/jnr.23841

48. Fillingim RB. Sex, Gender, and Pain, in Principles of GenderSpecific Medicine. Elsevier; 2017:481-496.

49. Neil MJE. Pain after amputation. BJA Educ. 2016;16(3):107-112. doi:10.1093/bjaed/mkv028

\section{Publish your work in this journal}

The Journal of Pain Research is an international, peer reviewed, open access, online journal that welcomes laboratory and clinical findings in the fields of pain research and the prevention and management of pain. Original research, reviews, symposium reports, hypothesis formation and commentaries are all considered for publication. The manuscript management system is completely online and includes a very quick and fair peer-review system, which is all easy to use. Visit http:// www.dovepress.com/testimonials.php to read real quotes from published authors. 